\title{
Resistência de cultivares de feijão-caupi ao ataque de Callosobruchus maculatus (Coleoptera: Chrysomelidae: Bruchinae) em condições de armazenamento
}

\author{
Resistance of cowpea cultivars against the attack of Callosobruchus \\ maculatus (Coleoptera: Chrysomelidae: Bruchinae) under storage conditions
}

Alberto Luiz Marsaro Júnior ${ }^{[a]}$,Aloisio Alcantara Vilarinho[ ${ }^{[b]}$

[a] Entomologista, Doutor, Embrapa Trigo, Passo Fundo, RS - Brasil, e-mail: alberto@cnpt.embrapa.br

[b] Melhorista genético, Doutor, Embrapa Roraima, Boa Vista, RR- Brasil, e-mail: aloisio@cpafrr.embrapa.br

\section{Resumo}

Callosobruchus maculatus é uma das principais pragas do feijão-caupi armazenado no Brasil. Estudos que avaliem a resistência de genótipos de feijão-caupi com relação ao ataque dessa praga são raros na região norte do Brasil. Nesse sentido, o objetivo desta pesquisa foi avaliar a resistência de cultivares de feijãocaupi com relação ao ataque de C. maculatus, em condições de armazenamento, no Estado de Roraima. Amostras de grãos de doze cultivares de feijão-caupi, BRS Mazagão, BRS Paraguaçu, BRS Novaera, BRS Guariba, BRS Milênio, BRS Cauamé, BR 3 Tracuateua, BR 17 Gurguéia, Vita 7, Amapá, Patativa e Linhagem 26, foram infestadas com adultos de C. maculatus e mantidas em condições de laboratório a $25{ }^{\circ} \mathrm{C}$ e 12 horas de fotofase. Após 20 dias da infestação foram avaliados os seguintes parâmetros de resistência: ciclo biológico, perda de massa seca dos grãos e número de insetos emergidos. As cultivares mais suscetíveis ao ataque de $C$. maculatus foram: BRS Mazagão e Vita 7, enquanto as mais resistentes foram: BR 17 Gurguéia e BRS Cauamé.

Palavras-chave: Resistência de plantas. Feijão-caupi armazenado. Vigna unguiculata.

\section{Abstract}

Callosobruchus maculatus is one of the major pests of stored cowpea in Brazil. Researches that evaluated the resistance of the genotypes of the cowpea in relation to the attack of this pest in the northern area of Brazil are rare. In this sense, the objective of this research was to evaluate the resistance of cowpea cultivars in relation to the attack of $\mathrm{C}$. maculatus under storage conditions in the state of Roraima. Samples of grains of twelve cowpea cultivars, BRS Mazagão, BRS Paraguaçu, BRS Novaera, BRS Guariba, BRS Milênio, BRS Cauamé, BR 3 Tracuateua, BR 17 Gurguéia, Vita 7, Amapá, Patativa and Linhagem 26, were infested with adults of the C. maculatus and maintained in laboratory conditions at $25^{\circ} \mathrm{C}$ and 12 hours of photophase. After 20 days of infestation the following parameters of resistance were evaluated: biological cycle, dry mass reduction of grains and 
number of emerged insects. The most susceptible cultivars to the attack of C. maculatus were: BRS Mazagão and Vita 7, while the most resistant were: BR 17 Gurguéia and BRS Cauamé.

Keywords: Plant resistance. Stored cowpea. Vigna unguiculata.

\section{Introdução}

O feijão-caupi (Vigna unguiculata (L.) Walp.) é uma cultura de destaque nas regiões Norte e Nordeste do Brasil e tem amplo significado social, constituindo-se em um dos principais alimentos proteicos e energéticos da população rural. No Estado de Roraima, seu cultivo representa papel importante não só na subsistência dos agricultores familiares, mas também como produto de valor comercial, sendo vendido para consumo tanto seco como verde, o que possibilita ao agricultor um período maior de venda (MENEZES et al., 2007).

0 feijão-caupi é danificado por diversos insetos durante todo o seu ciclo de desenvolvimento, mas em condições de armazenamento destacam-se as pragas de grãos: Plodia interpunctella e Callosobruchus maculatus (MARSARO Jr., 2007).

As infestações por C. maculatus podem iniciar no campo e as fêmeas põem, em média, 80 ovos, os quais são depositados na superfície dos grãos. Após a eclosão, as larvas penetram nas sementes, onde se alimentam e empupam. Além da perda de peso dos grãos por causa das galerias provocadas pelas larvas, os carunchos diminuem grandemente o poder germinativo das sementes (QUINTELA et al., 1991).

Não existem produtos registrados no Ministério da Agricultura, Pecuária e Abastecimento (Mapa) para o controle de $C$. maculatus, para a cultura do feijão-caupi, em pós-colheita, embora seja comum o uso de inseticidas fumigantes para o controle de insetos em grãos e sementes.

A seleção de plantas com características de resistência a insetos apresenta-se como uma medida alternativa ao controle químico, inclusive para grãos armazenados. Alguns estudos têm demonstrado a existência de genótipos de feijão-caupi resistentes à C. maculatus (BARRETO; QUINDERÉ, 2000; COSTA; BOIÇA Jr., 2004; LIMA et al., 2001).

A resistência de grãos a insetos tem sido atribuída a diversos fatores. Em grãos de milho, a presença de compostos fenólicos e inibidores de amilase foi a responsável pela resistência de genótipos ao ataque de Sitophilus zeamais, conforme demonstraram Serratos et al. (1993) e Marsaro Jr. et al. (2005), respectivamente. Em grãos de Phaseolus vulgaris, a presença da proteína arcelina confere resistência aos genótipos de feijão ao ataque de Zabrotes subfasciatus (WANDERLEY; OLIVEIRA; ANDRADE Jr., 1997), enquanto na espécie $V$. unguiculata os responsáveis pela resistência dos genótipos de feijão-caupi à praga $C$. maculatus são os inibidores de tripsina (GATEHOUSE et al., 1989).

A utilização de plantas resistentes a insetos apresenta uma série de vantagens com relação ao uso dos inseticidas químicos: não onera o custo de produção, não oferece riscos para a saúde humana e animal, reduz perdas quantitativas e qualitativas, não polui o meio ambiente e é compatível com outras estratégias de controle (LARA, 1991; MAZZONETO; BOIÇA Jr., 1999).

Graças às vantagens da utilização de plantas resistentes a insetos e à carência de estudos sobre resistência de grãos a pragas quando armazenados, na região Norte do Brasil, elaborou-se esta pesquisa com o objetivo de avaliar a resistência de doze cultivares de feijão-caupi, $V$. unguiculata, com relação ao ataque de C. maculatus em condições de armazenamento.

\section{Materiais e métodos}

As cultivares de feijão-caupi avaliadas nesta pesquisa, BRS Mazagão, BRS Paraguaçu, BRS Novaera, BRS Guariba, BRS Milênio, BRS Cauamé, BR 3 Tracuateua, BR 17 Gurguéia, Vita 7, Amapá, Patativa e Linhagem 26, foram oriundas de plantio realizado em maio de 2005, no campo experimental Água Boa, da Embrapa Roraima, Boa Vista, RR. Durante o ciclo da cultura todos os tratos culturais convencionais foram realizados.

Após a colheita, amostras de aproximadamente $1 \mathrm{~kg}$ de grãos de cada cultivar foram secas à sombra até atingirem $13,5 \%$ de umidade. Para a confirmação dessa umidade, três amostras de $5 \mathrm{~g}$ de grãos, 
de cada cultivar, foram colocadas em estufa a $105^{\circ} \mathrm{C}$ durante 24 horas (BRASIL, 1992). Posteriormente, os grãos foram armazenados em sacos plásticos, a $-20^{\circ} \mathrm{C}$, por 30 dias, a fim de eliminar os insetos provenientes do campo (FALEIRO et al., 1995).

Os indivíduos adultos de C. maculatus utilizados nesta pesquisa foram obtidos a partir da criação mantida no Laboratório de Entomologia da Embrapa Roraima.

A unidade experimental foi formada por uma amostra de $50 \mathrm{~g}$ de grãos de feijão-caupi e cinco insetos, com 48 horas de idade, que permaneceram confinados para oviposição por sete dias, à semelhança de Costa e Boiça Jr. (2004). Após esse período, os insetos adultos foram descartados, restando, dessa maneira, somente a fase de ovos dos insetos. Cada amostra foi armazenada em recipiente plástico de $500 \mathrm{~mL}$ com tampa telada, em condições de laboratório, a $25^{\circ} \mathrm{C}$ e 12 horas de fotofase.

Decorridos 20 dias após a infestação, avaliou-se, diariamente, o número de adultos emergidos, os quais eram descartados após a contagem. Essa avaliação foi realizada até o momento em que não mais se observou a emergência de adultos por três dias consecutivos. Também foi avaliada a perda de massa seca dos grãos, consumida pela progênie, determinada pela diferença entre a massa seca inicial e a massa seca final.

A resistência das cultivares de feijão-caupi foi avaliada também pelo cálculo do ciclo biológico, de ovo a adulto (em dias), à semelhança de Costa e Boiça Jr. (2004). Para a obtenção desse parâmetro foi aplicada a média ponderada, dada pela fórmula: ciclo biológico $=\sum \mathrm{x} \cdot \mathrm{f} / \sum \mathrm{x}$, onde $\mathrm{x}=$ número de adultos emergidos no dia; $\mathrm{e} f$ = número de dias para a emergência.

As doze cultivares de feijão-caupi foram avaliadas quanto à resistência ao C. maculatus em ensaio conduzido no delineamento inteiramente casualizado com três repetições cada. Os dados foram submetidos à análise de variância e, quando se detectaram diferenças significativas pelo teste $\mathrm{F}$, as médias foram comparadas pelo teste de Scott-Knott ao nível de 5\%.

\section{Resultados e discussão}

Considerando todos os parâmetros de resistência avaliados, as cultivares BRS Mazagão e Vita 7 foram as mais suscetíveis ao ataque de C. maculatus. Essas cultivares apresentaram as maiores médias para a variável insetos emergidos (BRS Mazagão $=138,67$ e Vita $7=129,00$ ) e as maiores médias para a variável massa seca consumida dos grãos (BRS Mazagão $=2,48$ g e Vita $7=2,55 \mathrm{~g}$ ) (Tabela 1). Também foi observado que o ciclo biológico de $C$. maculatus foi mais curto nessas cultivares (BRS Mazagão $=24,20$ dias e Vita $7=24,26$ dias) (Tabela 1), indicando que elas foram as mais adequadas para a oviposição e/ou desenvolvimento das larvas. Por isso, essas cultivares, quando infestadas com C. maculatus, apresentaram maior descendência de insetos quando comparadas com as cultivares mais resistentes. Em consequência disso, apresentaram os maiores danos quantitativos.

Os resultados encontrados nesta pesquisa estão de acordo com os observados por Costa e Boiça Jr. (2004). Os autores também constataram que os

Tabela 1 - Médias \pm erro-padrão* do número de adultos de Callosobruchus maculatus (Coleoptera: Chrysomelidae: Bruchinae) emergidos, massa seca consumida e ciclo biológico, obtidos em amostras de $50 \mathrm{~g}$ de grãos de 12 cultivares de feijão-caupi

\begin{tabular}{lccc}
\hline Cultivares & $\begin{array}{c}\text { Número } \\
\text { de insetos } \\
\text { emergidos }\end{array}$ & $\begin{array}{c}\text { Massa seca } \\
\text { consumida } \\
\mathbf{( g )}\end{array}$ & $\begin{array}{c}\text { Ciclo } \\
\text { biológico } \\
\text { (dias) }\end{array}$ \\
\hline BRS Mazagão & $138,67 \pm 8,95 \mathrm{a}$ & $2,48 \pm 0,14 \mathrm{a}$ & $24,20 \pm 0,05 \mathrm{e}$ \\
Vita 7 & $129,00 \pm 10,69 \mathrm{a}$ & $2,55 \pm 0,12 \mathrm{a}$ & $24,26 \pm 0,07 \mathrm{e}$ \\
Amapá & $119,00 \pm 2,31 \mathrm{a}$ & $2,02 \pm 0,09 \mathrm{~b}$ & $24,82 \pm 0,16 \mathrm{~d}$ \\
BR 3 Tracuateua & $118,67 \pm 4,26 \mathrm{a}$ & $1,87 \pm 0,09 \mathrm{~b}$ & $24,43 \pm 0,10 \mathrm{e}$ \\
BRS Paraguaçu & $114,00 \pm 7,09 \mathrm{a}$ & $1,68 \pm 0,14 \mathrm{c}$ & $24,71 \pm 0,10 \mathrm{~d}$ \\
BRS Milênio & $103,67 \pm 11,57 \mathrm{~b}$ & $1,58 \pm 0,17 \mathrm{c}$ & $24,53 \pm 0,07 \mathrm{e}$ \\
BRS Novaera & $93,00 \pm 7,21 \mathrm{~b}$ & $1,88 \pm 0,06 \mathrm{~b}$ & $24,88 \pm 0,15 \mathrm{~d}$ \\
BRS Guariba & $73,33 \pm 5,04 \mathrm{c}$ & $1,20 \pm 0,10 \mathrm{~d}$ & $24,56 \pm 0,20 \mathrm{e}$ \\
Linhagem 26 & $72,33 \pm 4,67 \mathrm{c}$ & $1,11 \pm 0,08 \mathrm{~d}$ & $25,56 \pm 0,13 \mathrm{c}$ \\
Patativa & $47,00 \pm 5,69 \mathrm{~d}$ & $0,72 \pm 0,09 \mathrm{e}$ & $24,35 \pm 0,09 \mathrm{e}$ \\
BR 17 Gurguéia & $30,33 \pm 1,45 \mathrm{~d}$ & $0,46 \pm 0,02 \mathrm{e}$ & $27,39 \pm 0,18 \mathrm{a}$ \\
BRS Cauamé & $29,67 \pm 1,67 \mathrm{~d}$ & $0,59 \pm 0,05 \mathrm{e}$ & $26,54 \pm 0,11 \mathrm{~b}$ \\
\hline CV\% & 13,03 & 11,96 & 0,87 \\
\hline
\end{tabular}

Legenda: ${ }^{*}$ = médias seguidas pela mesma letra, na coluna, pertencem ao mesmo grupo, pelo teste de Scott-Knott ao nível de 5\%.

Fonte: Dados da pesquisa. 
genótipos mais suscetíveis apresentaram as maiores médias para as variáveis número de insetos emergidos e massa seca consumida dos grãos e as menores médias para a variável ciclo biológico.

Considerando todos os parâmetros de resistência avaliados, as cultivares BR 17 Gurguéia e BRS Cauamé foram as mais resistentes ao ataque de $C$. тасиlatus. Essas cultivares apresentaram as menores médias para a variável número de adultos emergidos (BR 17 Gurguéia $=30,33$ e BRS Cauamé $=29,67$ ) e as menores perdas de massa seca (BR 17 Gurguéia = 0,46 g e BRS Cauamé $=0,59$ g) (Tabela 1 ). Também foi observado que o ciclo biológico de $C$. maculatus foi mais longo nessas cultivares (BR 17 Gurguéia = 27,39 dias e BRS Cauamé = 26,54 dias), indicando que elas foram as menos adequadas para a oviposição e/ou desenvolvimento das larvas. Resultados semelhantes aos encontrados neste trabalho também foram observados por Costa e Boiça Jr., 2004. Os autores também mencionaram que os resultados apresentados pelas variáveis analisadas: número de adultos emergidos, perda de massa seca dos grãos e ciclo biológico, são importantes indicadores da resistência apresentada pelos genótipos.

A variável ciclo biológico constitui importante parâmetro para se avaliar a resistência de genótipos a pragas, visto que quanto maior for o ciclo maior será o indício de resistência do genótipo. Segundo Araújo e Watt (1988 apud Costa e Boiça Jr., 2004), a resistência do tipo antibiose é caracterizada, sobretudo, pelo alongamento do período de ovo a adulto e pela redução do número de adultos de $C$. maculatus emergidos em posturas efetuadas nas sementes e vagens de feijão-caupi. Portanto, de acordo com essas informações, e baseados nos resultados encontrados nesta pesquisa, podemos inferir que as cultivares BR 17 Gurguéia e BRS Cauamé apresentaram resistência do tipo antibiose com relação à praga C. maculatus.

A resistência do tipo antibiose em genótipos de feijão-caupi tem sido atribuída à presença de inibidores da tripsina dos insetos (GATEHOUSE et al., 1989). A resistência das cultivares BR 17 Gurguéia e BRS Cauamé, observadas nesta pesquisa, pode estar relacionada à presença desses inibidores nos grãos dessas cultivares. Futuros estudos poderiam investigar se esses inibidores estão presentes nessas cultivares resistentes e se existe correlação entre essas variáveis.

\section{Conclusões}

Todas as cultivares de feijão-caupi avaliadas nesta pesquisa apresentaram um certo grau de suscetibilidade ao ataque de $C$. maculatus, porém nas cultivares mais resistentes ocorreu menor emergência de adultos, menor consumo de massa seca dos grãos e maior período para que o inseto complete o ciclo biológico.

\section{Referências}

BARRETO, P. D.; QUINDERÉ, M. A. W. Resistência de genótipos de caupi ao caruncho. Pesquisa Agropecuária Brasileira, v. 35, n. 4, p. 779-785, 2000.

BRASIL. Regras para análise de sementes. Brasília: Ministério da Agricultura e Reforma Agrária, 1992. v. 1, n. 1, p. 365.

COSTA, N. P. C.; BOIÇA Jr., A. L. Efeito de genótipos de caupi, Vigna unguiculata (L.) Walp., sobre o desenvolvimento de Callosobruchus maculatus (Fabricius) (Coleoptera: Bruchidae). Neotropical Entomology, v. 33, n. 1, p. 7783, 2004.

FALEIRO, F. G. et al. Resistência de 49 populações de milho a Sitophilus zeamais Motsch. (Coleoptera: Curculionidae). Revista Brasileira de Armazenamento, v. 20, p. 17-21, 1995.

GATEHOUSE, A. M. R. et al. Biochemical basis of insect resistance in Vigna unguiculata. Journal of the Science of Food and Agriculture, v. 30, p. 948-958, 1989.

LARA, F. M. Princípios de resistência de plantas a insetos. São Paulo: Ícone, 1991.

LIMA, M. P. L. et al. Estabilidade da resistência de genótipos de caupi a Callosobruchus maculatus (Fabr.) em gerações sucessivas. Scientia Agrícola, v. 59, n. 2, p. 275-280, 2001.

MARSARO Jr., A. L. et al. Inibidores de amilase em híbridos de milho como fator de resistência a Sitophilus zeamais Motschulsky (Coleoptera: Curculionidae). Neotropical Entomology, v. 34, n. 3, p. 443-450, 2005.

MARSARO Jr., A. L. Insetos-praga e seus inimigos naturais na cultura do feijão-caupi no Estado de Roraima. In: WORKSHOP SOBRE A CULTURA DO FEIJÃO-CAUPI EM RORAIMA, 1., 2007, Boa Vista. Anais... Boa Vista: UFRR, Embrapa, 2007. CD-ROM. 
MAZZONETO, F.; BOIÇA Jr., A. L. Determinação dos tipos de resistência de genótipos de feijoeiro ao ataque de Zabrotes subfasciatus (Boh.) (Coleoptera: Bruchidae). Anais da Sociedade Entomológica do Brasil, v. 28, n. 2, p. 307-311, 1999.

MENEZES, A. C. S. G. et al. Importância sócio-econômica e condições de cultivo do feijão-caupi em Roraima. In: WORKSHOP SOBRE A CULTURA DO FEIJÃO-CAUPI EM RORAIMA, 1., 2007, Boa Vista. Anais... Boa Vista: UFRR, Embrapa, 2007. CD-ROM.

QUINTELA, E. D. et al. Principais pragas do caupi no Brasil. Goiânia: EMBRAPA/CNPAF, 1991.

SERRATOS, J. A. et al. Generation means analysis of phenolic compounds in maize grain and susceptibility to maize weevil Sitophilus zeamais infestation. Canadian Journal of Botany, v. 71, p. 1176-1181, 1993.
WANDERLEY, V. S.; OLIVEIRA, J. V.; ANDRADE Jr., M. L. Resistência de cultivares e linhagens de Phaseolus vulgaris L. a Zabrotes fasciatus (Boh.) (Coleoptera: Bruchidae). Anais da Sociedade Entomológica do Brasil, v. 26, n. 2, p. 315-320, 1997.

Recebido: 05/02/2010

Received: 02/05/2010

Aprovado: $10 / 11 / 2010$

Approved: 11/10/2010 